\title{
Consumo de peixes: uma aplicação da teoria do comportamento planejado
}

Saúde e bem-estar cada vez mais influenciam decisões de consumo e o peixe por sua vez, recebe um destaque especial neste aspecto. 0 alimento se destaca pelo valor nutricional quanto à quantidade e qualidade das suas proteínas. Por outro lado, embora estatísticas mostrem expansão no setor brasileiro de pescado, especificamente para a produção de peixe, o consumo per capita não apresenta crescimento na mesma proporção, sendo esta, a carne menos consumida em algumas regiões do país. No Estado de Mato Grosso do Sul, o consumo de peixe está bem abaixo da média nacional per capita, apenas 3,98 kg/habitante/ano. Diante deste cenário, o objetivo deste estudo é investigar se a Teoria do Comportamento Planejado (TCP) poderia prever a intenção para o consumo da proteína peixe em uma amostra de consumidores sul-mato-grossenses. Os resultados fornecem uma compreensão mais clara das intenções de consumo do peixe. Além disso, todos os constructos da TCP original (atitudes, norma subjetiva e controle comportamental percebido) foram preditores significativos da intenção de consumo da proteína. O constructo valores saudáveis foi encontrado como uma importante variável adicional quando se trata do consumo de peixe. Os resultados oferecem ainda, uma variedade de informações úteis para desenvolvimento de novos estudos e a criação de campanhas públicas destinadas a aumentar o consumo da proteína na dieta dos indivíduos.

Palavras-chave: Agronegócio; Dieta Alimentar; Peixe; TCP.

\section{Fish consumption: an application of the theory of planned behavior}

Health and well-being are increasingly influencing consumption decisions and the fish in turn receives a special highlight in this regard. The food is distinguished by the nutritional value as to the quantity and quality of its proteins. On the other hand, although statistics show expansion in the Brazilian fishery sector, specifically for fish production, per capita consumption does not show growth in the same proportion, this being the least consumed meat in some regions of the country. In the State of Mato Grosso do Sul, fish consumption is well below the national average per capita, only $3.98 \mathrm{~kg} / \mathrm{inhabitant} / \mathrm{year}$. In view of this scenario, the objective of this study is to investigate whether the Theory of Planned Behavior (TCP) could predict the intention for consumption of fish protein in a sample of South American consumers. The results provide a clearer understanding of fish consumption intentions. In addition, all the original TCP constructs (attitudes, subjective norm, and perceived behavioral control) were significant predictors of protein consumption intent. The construct healthy values were found as an important additional variable when it comes to fish consumption. The results also provide a variety of useful information for the development of new studies and the creation of public campaigns aimed at increasing the consumption of protein in the diet of individuals.

Keywords: Agribusiness; Food Diet; Fish; TCP.

Topic: Marketing e Estratégias Mercadológicas

Reviewed anonymously in the process of blind peer.
Received: 09/12/2019

Approved: 24/01/2020

Lincoln Pegorari Nunes (iD)

Universidade Federal da Grande Dourados, Brasil

http://lattes.cnpq.br/4625031499717224

http://orcid.org/0000-0003-4832-0217

lincolnpegorari@gmail.com

Fabio Mascarenhas Dutra (iD

Universidade Federal da Grande Dourados, Brasil

http://lattes.cnpq.br/1193767417072889

http://orcid.org/0000-0002-8707-4453

fabiodutra@ufgd.edu.br

João Augusto Rossi Borges

Universidade Federal da Grande Dourados, Brasil

http://lattes.cnpq.br/6501458783677760

joaoborges@ufgd.edu.br

\section{Referencing this:}

NUNES, L. P.; DUTRA, F. M.; BORGES, J. A. R.. Consumo de peixes: uma aplicação da teoria do comportamento planejado. Revista Brasileira de Administração Científica, v.11, n.1, p.189-204, 2020. DOI: http://doi.org/10.6008/CBPC2179-684X.2020.001.0014 


\section{INTRODUÇÃO}

Nas últimas décadas, os hábitos de consumo mudaram significativamente, e as questões alimentares, tais como saúde, conveniência, variedade, valor, ética e segurança têm se tornando gradativamente importantes para o consumo alimentar. É recente a busca pelo homem por uma alimentação segura e saudável, elaborada com técnicas culinárias adequadas e integrada ao meio ambiente de forma sustentável (PHILIPPI, 2008). A constante busca por qualidade de vida vem sendo fator determinante na mudança dos hábitos alimentares para uma dieta mais saudável. Tal aspecto tem sido considerado uma condição decisiva no comportamento do consumidor orientado para a saúde neste século (NOVAES, 2006).

Diante deste cenário, saúde e bem-estar cada vez mais influenciam decisões de consumo e o peixe por sua vez, recebe um destaque especial neste aspecto, pois crescentes evidências na literatura confirmam benefícios para saúde a partir da inclusão desta proteína nos hábitos alimentares (FAO, 2014). Dessa forma, a proteína de peixe é um alimento excelente do ponto de vista nutricional, podendo ser considerada funcional na dieta alimentar (SOCCOL et al., 2003). Sartori et al. (2012) ressaltam que o alimento se destaca pelo valor nutricional quanto à quantidade e qualidade das suas proteínas, a presença de vitaminas, minerais e, principalmente, por ser fonte de ácidos graxos essenciais.

Estudos como de Stansby (1973), Dyerberg et al. (1979), Kris-Etherton et al. (2002), mostram que o baixo teor de gorduras saturadas, a grande presença de proteínas de alto valor biológico, a fácil digestão e os altos níveis de micronutrientes e ácidos graxos poli-insaturados, principalmente o ômega-3, trazem benefícios à saúde humana, como a diminuição do colesterol total e redução do risco para doenças coronarianas (GRACIA, 2003). Além da importância da carne de peixe na dieta da população mundial, este mercado ainda contribui com cerca de um quarto da oferta de proteína de origem animal no mundo e é parte essencial na geração de emprego, lucro e renda em alguns países (SANTOS, 2006; GONÇALVES et al., 2008).

Segundo a Organização das Nações Unidas para a Agricultura e Alimentação (FAO), a produção mundial de peixe em 2016 ultrapassou 170 milhões de toneladas, incluindo a produção extrativa e da aquicultura. Em 2016, a produção brasileira de peixe foi aproximadamente 1,2 milhões de toneladas, sendo a produção extrativa responsável por 619 mil toneladas e a aquicultura por 581 mil toneladas (FAO, 2018). Por outro lado, apesar dos números voltados à produção, o consumo de peixe no mundo se mostra de maneira desigual. Tal fato ocorre devido às diferenças continentais, nacionais, regionais e de renda da população. Como resultado, o consumo per capita ao ano de peixe varia de $1 \mathrm{~kg}$ até valores superiores a 100 $\mathrm{kg}(\mathrm{FAO}, 2018)$.

Segundo o State of the World Fisheries and Aquaculture (SOFIA), em 2016 a média de consumo per capita mundial de peixe bateu o recorde e chegou ao patamar aproximado de 20,3 kg/hab. ano. Dados mais recentes demonstraram que no Brasil, em 2013, o consumo per capita foi de aproximadamente 14,5 kg/hab. ano, ultrapassando o recomendando pela Organização Mundial de Saúde (OMS) de $12 \mathrm{~kg} / \mathrm{hab}$./ano (FAO, 2018; MPA, 2015).

Embora estatísticas mostrem expansão no setor brasileiro de pescado, especificamente para a 
produção de peixe, o consumo per capita não apresenta crescimento na mesma proporção, sendo esta, a carne menos consumida em algumas regiões no país (CARVALHO et al., 2009). Para vias de definição, o termo 'pescado' conforme Decreto Brasileiro do Regulamento de Inspeção Industrial e Sanitária dos Produtos de Origem Animal (RIISPOA), engloba os peixes, crustáceos, moluscos, anfíbios, quelônios e mamíferos de água doce ou salgada destinados à alimentação humana (BRASIL, 1952).

Conforme a FAO, o consumo recomendado de peixe é de duas vezes por semana, pois sua ingestão é de extrema importância para suscitar, manter ou recuperar a saúde dos indivíduos (FAO, 2014). De acordo com Burger et al. (2009) os consumidores estão conscientes dos benefícios à saúde proporcionados pelo consumo de peixe, no entanto, apesar da imagem predominantemente saudável como um produto alimentar e as atitudes favoráveis dos indivíduos para comer peixe (TRONDSEN et al., 2004), o consumo per capita em algumas regiões do Brasil permanece abaixo dos níveis de ingestão recomendados pela OMS de 12 $\mathrm{kg} / \mathrm{hab} . / \mathrm{ano}$.

As preferências em relação ao consumo de peixe englobam fatores individuais, muitas vezes, relacionados a padrões de consumo, condição socioeconômica, estado de saúde e entre outros. Fatores como os aspectos culturais e econômicos, tais como, nível de preço, oferta de peixes no mercado e nível de renda do consumidor podem interferir diretamente neste consumo (MPA, 2015).

Pesquisas apontam que o preço, o cheiro, all flavour, desconhecimento no preparo, tempo de preparo, qualidade da carne, constância na oferta, etc., são alguns dos principais aspectos que contribuem para o baixo consumo da proteína de peixe em algumas regiões do mundo (VERBEKE et al., 2005; GAVIGLIO et al., 2014; TOMIĆ et al., 2016). Partes destes aspectos também foram encontradas em alguns estudos no Brasil, como por exemplo, Lopes et al. (2016) que expuseram o perfil do consumo de peixe da população brasileira e observaram que a região norte tem maior preferência por peixe frente outras proteínas devido a sua grande disponibilidade. Por outro lado, as demais regiões do país têm o peixe em terceiro lugar na sua preferência, vindo logo atrás da carne bovina e das aves, principalmente, devido questões culturais, preço e qualidade da carne.

Segundo o IBGE, através da Pesquisa de Orçamentos Familiares (POF) 2008/2009, no Estado de Mato Grosso do Sul, o consumo de peixe está bem abaixo da média nacional per capita, apenas 3,98 $\mathrm{kg} /$ habitante/ano. A cultura para o consumo da carne de peixe e seus derivados no estado preserva hábitos muito específicos de resistência devido à falta de costume, a preocupação por não encontrar peixes de qualidade e a facilidade para inserir substitutos à dieta (CARRIJO-MAUAD et al., 2013). Diante deste cenário, o presente estudo pretende responder a seguinte questão de pesquisa: quais os fatores que influenciam o consumo de peixes na dieta alimentar de uma amostra sul-mato-grossense?.

Conhecer as preferências e comportamentos de consumo para os alimentos tem se destacado como uma importante área de estudo, através do conhecimento dos atributos que levam à intenção de consumo. O estudo deste tema se mostra de grande relevância na medida em que pode colaborar para uma melhor compreensão das necessidades e expectativas dos consumidores e que estas, por sua vez, sejam exploradas e consequentemente atendidas. Tal pesquisa pode ser fonte para desenvolvimento de novos estudos, visto 
que conforme levantamentos nas bases de dados nacionais e internacionais, encontrou-se no Brasil, apenas um projeto da UTFPR na área, não sendo localizado mais pesquisas com mesma metodologia, tornando-a de fato inédita.

Diante do exposto, o objetivo principal deste estudo é investigar se a Teoria do Comportamento Planejado (TCP) poderia prever a intenção para o consumo da proteína peixe em uma amostra de consumidores sul-mato-grossenses. Para isso, os objetivos específicos se dividem em: - Identificar e caracterizar o perfil socioeconômico do consumidor; - Analisar os resultados da amostra de consumidores quanto aos constructos da TCP.

\section{REVISÃO TEÓRICA}

\section{Consumo de Peixe no Brasil}

Na busca por sobrevivência o homem encontrou na água uma fonte alternativa para obtenção de alimentos (GRACIA, 2003). A importância dos oceanos, mares e rios está nos 100 milhões de toneladas de peixe que o homem consome, nos diversos tipos de algas e animais marinhos que possui e nas substâncias que são utilizadas para a fabricação de produtos. No Brasil, o consumo de peixe é regionalizado. Em alguns estados brasileiros, o peixe constitui a base alimentar da população, enquanto em outros o consumo fica abaixo da média nacional. Por exemplo, no Pará/Amazônia o consumo per capita chega a $40 \mathrm{~kg}$ ao ano, em Pernambuco e Sergipe, apesar da proximidade do mar o consumo é baixo, por volta de 2,8 kg por habitante, já em São Paulo seu consumo per capita é de aproximadamente $12 \mathrm{~kg}$ ao ano (BRANDÃO, 2015).

A escolha e o comportamento alimentar se desenvolvem de acordo com as regras impostas pela sociedade, meio ambiente, história individual e valores do grupo social no qual o indivíduo está inserido (FALK et al., 2001; FURST et al., 1996). Conforme Gracia (2003), torna-se necessário conhecer a disponibilidade dos recursos locais, especialmente no que se refere aos alimentos regionais e padrões culturais.

A primeira influência no consumo alimentar dos indivíduos parte principalmente da família. A mãe ou o responsável por preparar as refeições é o principal responsável pela dinâmica das escolhas alimentares, pois cabe a estes indivíduos, a escolha e compra dos alimentos, preparo e fornecimento das refeições (ESTIMA et al., 2009). Dentre as razões para o baixo consumo de peixe em algumas regiões do Brasil, as principais são: a falta de costume e informações, e o elevado preço se comparado aos outros tipos de proteína de origem animal. A carência de instrumentos de marketing, a falta de difusão de informações sobre o produto e a indústria também contribui para o baixo consumo de pescados (OETTERER, 2002).

O consumo de peixe vem sendo estimulado atualmente devido ao seu alto valor nutritivo. Estudos mostram que o baixo teor de gorduras saturadas, a grande presença de proteínas de alto valor biológico, a fácil digestão e os altos níveis de micronutrientes e ácidos graxos poli-insaturados, principalmente o ômega3 , trazem benefícios à saúde humana, como a diminuição do colesterol total e redução do risco para doenças coronarianas (GRACIA, 2003). 
Diante deste cenário, suportado pela produção brasileira que demonstra crescimento sucessivo, o consumo sul-mato-grossense fica aquém do recomendado frente a média mundial e nacional. Tal fato corrobora a necessidade de se entender o comportamento do consumidor, analisando as influências na intenção e correlacionando-as para verificar o comportamento de consumo através da Teoria do Comportamento Planejado.

\section{Teoria do Comportamento Planejado (TCP)}

Uma série de modelos teóricos tem sido desenvolvidos e aplicados para prever e explicar comportamentos. Um dos modelos frequentemente utilizado é a Teoria do Comportamento Planejado (TCP). A Teoria do Comportamento Planejado proposta em 1985 pelo psicólogo social Icek Ajzen, busca prever e explicar o comportamento humano em determinada circunstância. Para um indivíduo realizar um comportamento, diante das oportunidades e recursos que possui, dependerá da ação conjunta da intenção e do controle comportamental (AJZEN, 1991). A Figura 1, demonstra a estrutura do modelo da teoria.

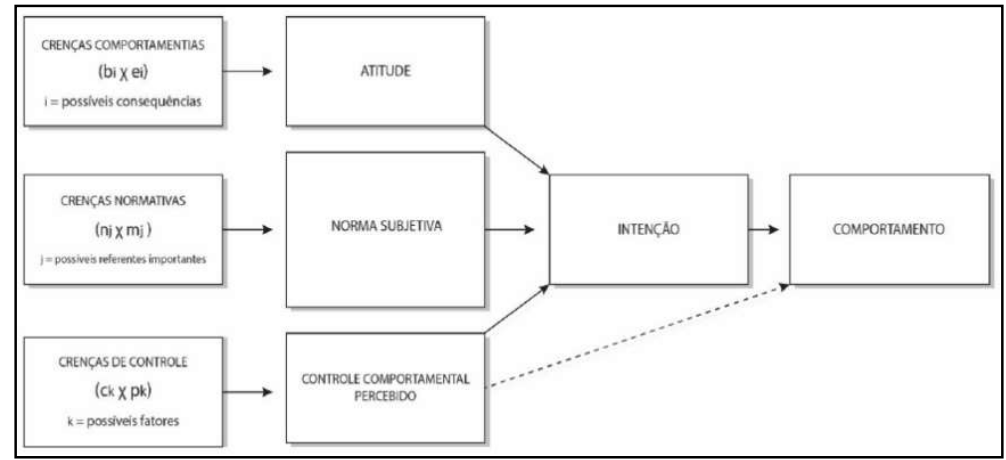

Figura 1: Modelo da Teoria do Comportamento Planejado. Fonte: Adaptado de Ajzen (2005), Borges et al. (2014).

O uso prévio de uma teoria se mostra de alta compreensibilidade e utilidade para entender o comportamento humano. No caso da TCP, a teoria é determinada por três preditores independentes: atitude, norma subjetiva e controle comportamental percebido (REYNOLDS, 1971). Atitude refere-se ao grau em que uma pessoa tem uma avaliação positiva, negativa ou em aberto em questão do comportamento. Norma subjetiva refere-se à pressão social percebida para realizar ou não o comportamento, enquanto controle comportamental percebido refere-se à facilidade ou dificuldade percebida para realizar o comportamento, presumindo a experiência do passado, bem como os impedimentos e obstáculos previstos (AJZEN, 1991).

As intenções de um indivíduo são formadas pelas crenças que eles possuem sobre o comportamento em questão. Estas crenças são referentes às consequências percebidas para realizar o comportamento, dando origem a atitude, norma subjetiva e controle comportamental percebido (AJZEN, 2005). Com isso, pode-se descrever: Crenças comportamentais - essas crenças determinam a atitude em relação ao comportamento através da percepção das prováveis consequências. Ou seja, cada crença comportamental liga o comportamento a determinado resultado, favorável ou desfavorável; Crenças normativas - essas crenças determinam a norma subjetiva e estão relacionadas a uma pessoa ou um grupo que pode(m) aprovar 
ou desaprovar a realização do comportamento. Estas pessoas podem ser parentes, cônjuge, amigos próximos, colegas de trabalho, ou até mesmo profissionais; Crenças de controle - crenças que determinam o controle comportamental percebido. Estas crenças estão relacionadas a experiências passadas do indivíduo; e/ou por influência de informações, através das experiências de amigos e conhecidos; e/ou por meio de outros fatores que possam aumentar ou reduzir a facilidade ou dificuldade percebida.

De acordo com a Figura 1, a atitude é derivada das crenças comportamentais (bi $x$ ei), onde bi é a probabilidade de resultado do comportamento (i), e ei é a avaliação do resultado. A norma subjetiva é derivada das crenças normativas (nj $x$ mj), onde nj são as expectativas dos referentes importantes (j) e mj é a motivação para cumprir a opinião desses referentes. E o controle comportamental percebido é derivado das crenças de controle (ck $x$ pk), onde ck são fatores (k) que podem facilitar ou dificultar o desempenho do comportamento e pk é o poder percebido destes fatores para facilitar ou dificultar o comportamento (WAUTERS et al., 2010; BORGES et al., 2014).

A TCP é uma complexa estrutura para compreender, prever e mudar o comportamento humano. Sua eficiência baseia-se no pressuposto de que os indivíduos tomam suas decisões de forma eminentemente racional e utilizam sistematicamente as informações que estão disponíveis, considerando as implicações de suas ações antes de decidirem se devem ou não se comportar de determinada forma (AJZEN, 2012).

A teoria do comportamento planejado é suportada por evidências empíricas; onde em 2012 já existiam mais de 1200 bibliografias de pesquisa em bancos de dados acadêmicos (AL-LOZI et al., 2012). O suporte empírico vem de uma gama de estudos demonstrando a capacidade da teoria de prever a intenção e comportamento, bem como as intervenções que mostrem mudanças nas crenças normativas e de controle, que podem produzir mudanças na intenção e que refletirão no comportamento subjacente (AJZEN, 2012).

De acordo com Ajzen (1991) e Perugini et al. (2001), modificando o modelo da TCP, alterando caminhos e incluindo constructos crítico-adicionais num certo contexto, muitas vezes, pode-se contribuir para melhorar a compreensão do mecanismo do modelo. Além disso, aumenta o poder de predição da intenção dos indivíduos em um contexto específico, no qual a teoria pode ser aprofundada. Muitos pesquisadores tentaram aumentar a proporção de variância explicada pela inclusão de constructos adicionais tais como: comportamento passado (SOMMER, 2011; WONG et al., 2009), a importância da crença (STEADMAN et al., 2004), atitude afetiva (CONNER et al., 2015) e valores (LEEUW et al., 2015).

Com relação ao tema desta pesquisa, após levantamento das informações na fase qualitativa e com base em pesquisas de autores como Olsen (2004), Roininen et al. (1999), Verbeke et al. (2005) e Wiegersma et al. (2000) se criou o constructo valores saudáveis. A Figura 2 apresenta o modelo utilizado neste estudo. Valores saudáveis representa uma inter-relação entre dois constructos: norma moral e saúde. Norma moral se refere aos valores pessoais que são baseados em normas sociais internalizadas e expectativas (VERBEKE et al., 2005). Como o peixe é percebido como um alimento saudável o envolvimento de saúde seria um constructo potencialmente importante. De acordo com Olsen (2004), indivíduos com alta obrigação moral e que estão inclinados para uma alimentação saudável são consumidores de peixe leais. 


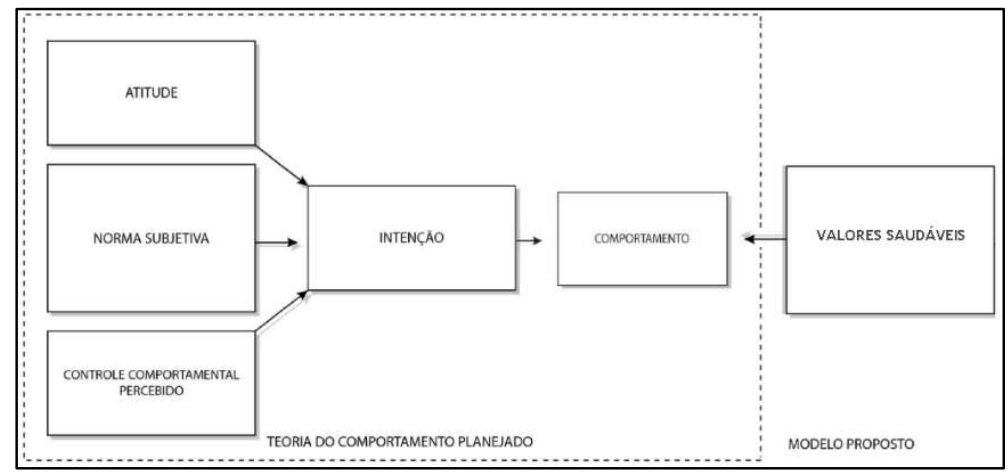

Figura 2: TCP - Teoria do Comportamento Planejado - Modelo Proposto

Resultados com os constructos analisados separadamente foram obtidos nos estudos de Roininen et al. (1999) e Wiegersma et al. (2000), onde a razão para que os constructos tais como norma moral e saúde obteve um efeito significativo baixo, é a provável aceitação praticamente universal da ideia de que o peixe é saudável e os valores pessoais, muitas vezes, normas sociais, são baseadas neste pressuposto, onde a única crença de saúde, portanto, não explica por que algumas pessoas consomem mais peixe do que outros.

\section{METODOLOGIA}

$\mathrm{Na}$ presente pesquisa utilizou-se como abordagem teórico-metodológica a Teoria do Comportamento Planejado (TCP) para verificar quais são os fatores de influência sobre a inclusão da carne de peixe na dieta dos indivíduos. O estudo foi realizado no estado do Mato Grosso do Sul, levando-se em consideração as intenções de comportamento: atitude, norma subjetiva e controle comportamental percebido, os quais podem ser explicitados diretamente ou ainda derivar das crenças dos indivíduos (medidas indiretas).

Quanto a abordagem da pesquisa é caracterizada como quanti-quali, onde os dados primários foram obtidos por meio da coleta de informações através de entrevistas e questionários semiestruturados. Os dados secundários são provenientes de informações contidas na literatura científica, nos mecanismos de pesquisa online, bem como documentos que tratam variáveis em relação a situação da piscicultura no Mato Grosso do Sul. O estudo foi desenvolvido em duas etapas, sendo os questionários da primeira e segunda fase já estabelecidos e validados pela teoria utilizada, adaptando-os ao tema e objetivos do estudo. Para isso, a elaboração das declarações para aplicar a TCP, seguiram as premissas sugeridas por Fishbein et al. (2010).

Tais autores orientam a importância de identificar as crenças das possíveis consequências de comportamento, os referentes e os possíveis fatores que facilitam ou dificultam o comportamento junto ao público-alvo da pesquisa. Assim, na primeira fase da pesquisa foram realizadas entrevistas semiestruturadas, utilizando-se um roteiro de perguntas qualitativas junto a uma amostra escolhida por conveniência entre 15 estudantes de diferentes cursos da Universidade Federal da Grande Dourados sobre o consumo da proteína de peixe.

A primeira fase teve como objetivo identificar as crenças comportamentais, normativas e de controle que originam, respectivamente, os constructos atitude, norma subjetiva e controle comportamental percebido. Dessa forma, foram utilizadas sete declarações no total (Apêndice 01). Para as crenças 
comportamentais foram utilizadas três perguntas para apontar as possíveis consequências do comportamento (i); através de duas perguntas foram identificadas as crenças normativas, em que possíveis pessoas ou grupos que poderiam influenciar o comportamento (j); e as crenças de controle foram realizadas por meio de duas perguntas que identificaram os fatores que poderiam facilitar ou dificultar o comportamento (k). Os resultados da primeira fase estão dispostos na Tabela 1 e, seguindo recomendações da TCP, foram utilizados para elaborar o questionário da segunda fase.

Tabela 1: Consequências (i), referentes importantes (j) e fatores $(k)$ identificados nas entrevistas semiestruturadas com perfis para o consumo da proteína de peixe.

\begin{tabular}{|l|l|l|}
\hline Consequências (i) & Referentes importantes (j) & Fatores (k) \\
\hline Alimentação mais saudável & Profissionais da saúde & Qualidade na alimentação \\
\hline Diversificação de cardápio & Família & Bom sabor da carne \\
\hline Sensação de saciedade & Amigos & Disponibilidade da carne \\
\hline Custo elevado na alimentação & - & Procedência da carne \\
\hline Reações adversas (azia etc.) & - & - \\
\hline Dificuldades de preparo & - & - \\
\hline
\end{tabular}

Nas entrevistas realizadas, seis possíveis consequências foram identificadas (Tabela 1). Estas consequências foram utilizadas no estudo para medir as crenças comportamentais. Para cada possível consequência identificada, os possíveis consumidores de peixe foram questionados por duas perguntas, sendo que estas possuíam uma escala de cinco pontos ancorada nos extremos. Em primeiro lugar, 'Quanto provável é que se você incluir a carne de peixe em sua dieta alimentar, você terá [consequência i] (pouco provável - muito provável)'. Em segundo lugar, 'Caso você inclua a carne de peixe em sua dieta alimentar, quão importante é para você ter [consequência i]? (pouco importante - muito importante)'. Para cada resultado i, as duas questões obtiveram bi e ei (Figura 1). Para cada possível consequência i, o produto de bi e ei foi calculado, resultando nas seis crenças comportamentais (bi $x$ ei), que foram utilizadas para medir a atitude.

Nas entrevistas realizadas, três referentes importantes foram identificados (Tabela 1). Estes três referentes foram utilizados no estudo para medir as crenças normativas. Para cada referente identificado, os possíveis consumidores foram questionados por duas perguntas, estas possuíam escala de cinco pontos ancorada nos extremos. Em primeiro lugar, 'Quanto provável é que cada uma das seguintes pessoas/grupos pensaria que você deveria incluir a carne de peixe em sua dieta alimentar [referente j] (pouco provável muito provável)'. Em segundo lugar, 'Quanto você se importa com o que as seguintes pessoas/grupos pensam sobre incluir a carne de peixe em sua dieta alimentar [referente j]? (totalmente não me importo me importo totalmente)'. Para cada referente j, as duas questões obtiveram nj e mj (Figura 1). Para cada referente j, o produto de nj e mj foi calculado, resultando em três crenças normativas (nj $x$ mj), que foram utilizadas para medir a norma subjetiva.

Nas entrevistas realizadas, quatro fatores foram identificados (Tabela 1). Estes quatro fatores foram utilizados no estudo para medir as crenças de controle. Para cada fator identificado, os possíveis consumidores foram questionados por duas perguntas, sendo que estas possuíam escala de cinco pontos ancorada nos extremos. Em primeiro lugar, 'Caso você inclua a carne de peixe em sua dieta alimentar, quão 
provável é que você terá [fator k] (pouco provável - muito provável)'. Em segundo lugar, 'Caso você inclua a carne de peixe em sua dieta alimentar, quão forte é a influência de cada um dos fatores abaixo na sua decisão? [fator k] (muito fraco - muito forte)'. Para cada fator k, as duas questões obtiveram ck e pk (Figura 01). Para cada fator $\mathrm{k}$, o produto de ck e pk foi calculado, resultando em quatro crenças de controle (ck $x \mathrm{pk})$, que foram utilizadas para medir o controle comportamental percebido.

A versão final do questionário utilizado para a coleta de dados foi composta por informações para identificação do perfil socioeconômico do respondente, frequência do consumo de peixe e questões relativas aos constructos do modelo proposto no estudo (Figura 2). Definiu-se para a segunda fase como população possíveis consumidores de peixe, sem faixa etária de classe social/renda ou idade. Logo, com o questionário quantitativo, a amostra totalizou 100 respondentes escolhidos por conveniência e distribuídos entre a população de Mato Grosso do Sul.

A coleta de dados foi realizada na primeira quinzena de setembro de 2018 pela empresa Opinion Box, fundada em 2012 e voltada para pesquisa e inteligência de mercado. O questionário foi encaminhado para a empresa utilizada, onde as perguntas foram enviadas via plataforma para uma base de respondentes do estado do Mato Grosso do Sul. McEacahan et al. (2011) mostraram que a eficácia da TCP também depende da metodologia de fatores, isto é, que os comportamentos avaliados a mais curto prazo e aqueles avaliados como auto relatados (comparados com medidas objetivas) são mais bem previstos. Neste estudo, o comportamento será baseado no consumo de peixe auto relatado em casa.

Os resultados contaram com a análise das características socioeconômicas dos respondentes, frequência do consumo de peixe auto relatado em casa e declarações baseadas no modelo proposto no estudo (Figura 2). Para a confiabilidade das declarações utilizadas para medir os constructos, foi utilizado o coeficiente $\alpha$ de Cronbach. Um coeficiente $\alpha$ de Cronbach elevado (acima de 0,6 ) indica que as diferentes afirmações utilizadas para intenção, norma subjetiva, controle comportamental percebido e valores saudáveis podem ser somadas e a média utilizada para representar estes constructos (BRUIJNIS et al., 2013). Para formação dos dados através de correlação simples utilizou-se o software STATA 13.

\section{RESULTADOS}

\section{Características Socioeconômicas e de Consumo da Amostra}

A Tabela 2 revela que a amostra de respondentes apresentou um perfil diversificado. Sendo grande parte do sexo feminino, jovens e adultos com idade predominante de 16 a 38 anos e nível de renda entre R\$ $3.748,00$ a $\mathrm{R} \$ 9.370,00$. Além disso, para a maioria destes indivíduos a frequência de consumo auto relatado em casa da proteína de peixe varia entre mensalmente e nem todo mês. As características socioeconômicas e de frequência de consumo da proteína de peixe na dieta alimentar da amostra são apresentadas na Tabela 2. 
Tabela 2: Características socioeconômicas e da frequência de consumo dos respondentes.

\begin{tabular}{|l|l|}
\hline Sexo & Feminino $-54 \%$ \\
& Masculino $-46 \%$ \\
\hline Idade & de 16 até 28 anos $-40 \%$ \\
& de 29 até 38 anos $-33 \%$ \\
& de 39 até 49 anos $-18 \%$ \\
& de 50 anos ou mais $-9 \%$ \\
& Média $=25$ anos \\
& Desvio Padrão $=4,37$ \\
\hline Renda & $\mathrm{R} \$ 13.740,01$ ou mais $-4 \%$ \\
& $\mathrm{R} \$ 9.370,01$ a $\mathrm{R} \$ 13.740,00-16 \%$ \\
& $\mathrm{R} \$ 3.748,01$ a $\mathrm{R} \$ 9.370,00-39 \%$ \\
& $\mathrm{R} \$ 1.874,01$ a $\mathrm{R} \$ 3.748,00-20 \%$ \\
& Até $\mathrm{R} \$ 1.874,00-21 \%$ \\
\hline Frequência de Consumo & Diariamente $-2 \%$ \\
& Semanalmente $-15 \%$ \\
& Mensalmente $-29 \%$ \\
& Várias vezes por mês $-10 \%$ \\
& Nem todo mês $-39 \%$ \\
& Nunca $-5 \%$ \\
\hline
\end{tabular}

\section{Intenção, Atitude, Norma Subjetiva, Controle Comportamental Percebido, Valores Saudáveis e suas Correlações}

As tabelas a seguir apresentam as medidas de correlação da amostra de respondentes para intenção e os constructos atitude, norma subjetiva, controle comportamental percebido e valores saudáveis. Para as três declarações utilizadas para mensurar intenção, obteve-se média alta, sendo a média maior para a INT3 e a menor para a INT1. Assim, a intenção da amostra com vistas ao consumo da proteína de peixe na dieta alimentar pode ser considerada alta, com base na média INT calculada (Tabela 3). O coeficiente $\alpha$ de Cronbach para a intenção foi superior a 0,6 (Tabela 3). Portanto, os resultados das três declarações podem ser somados e a média utilizada para representá-la.

Tabela 3: Escala, média e $\alpha$ de Cronbach para as três declarações usadas para medir a intenção dos potenciais consumidores da proteína de peixe na dieta alimentar.

\begin{tabular}{|l|l|l|l|}
\hline Intenção (INT) & Escala (1-5) & Média & $\begin{array}{l}\text { Desvio } \\
\text { Padrão }\end{array}$ \\
\hline $\begin{array}{l}\text { INT1 - Você tem a intenção de incluir carne de peixe na sua dieta } \\
\text { alimentar? }\end{array}$ & $\begin{array}{l}\text { Definitivamente não } \\
\text { Definitivamente sim }\end{array}$ & 3,86 & 1,14 \\
\hline $\begin{array}{l}\text { INT2 - Quanto forte é a sua intenção de incluir carne de peixe na } \\
\text { sua dieta alimentar? }\end{array}$ & Muito fraca - Muito forte & 3,96 & 1,07 \\
\hline $\begin{array}{l}\text { INT3 - Quanto provável é que você irá incluir carne de peixe na } \\
\text { sua dieta alimentar? }\end{array}$ & Pouco provável - Muito provável & 4,01 & 1,07 \\
\hline $\boldsymbol{\alpha}$ de Cronbach (INT) $=\mathbf{0 , 8 9}$ & & \\
\hline Média da Intenção (INT) $=\mathbf{3 , 9 4}$ &
\end{tabular}

Para as quatro declarações utilizadas para medir a atitude, obteve-se média alta, sendo a maior para a ATT1 (muito bom) e a menor para a ATT3 (muito necessário) (Tabela 4). Com isso, os resultados mostram que os potenciais consumidores da proteína de peixe na amostra possuem uma atitude positiva. 0 coeficiente $\alpha$ de Cronbach do constructo atitude foi superior a 0,6 (Tabela 4). Portanto, os resultados para as quatro declarações podem ser somados e a média utilizada para representar esse construto.

Nas duas declarações utilizadas para medir a norma subjetiva, as médias se mostraram altas e com valores próximos (Tabela 5). Dessa forma, pode-se considerar que os potenciais consumidores da proteína de peixe na amostra perceberam que é alta a pressão social para incluir este tipo de carne na dieta alimentar. 
O coeficiente $\alpha$ de Cronbach para o constructo norma subjetiva foi superior a 0,6 (Tabela 5). Portanto, os resultados para as duas declarações utilizadas podem ser somados e a média utilizada para representar esse constructo.

Tabela 4: Escala, média e $\alpha$ de Cronbach para as quatro declarações usadas para medir a atitude intenção dos potenciais consumidores da proteína de peixe na dieta alimentar.

\begin{tabular}{|l|l|l|l|}
\hline Atitude (ATT) & Escala (1-5) & Média & Desvio Padrão \\
\hline ATT1 - Incluir carne de peixe na sua dieta alimentar é: & Muito ruim - Muito bom & 4,31 & 0,98 \\
\hline ATT2 - Incluir carne de peixe na sua dieta alimentar é: & Muito desvantajoso - Muito vantajoso & 4,25 & 1,02 \\
\hline ATT3 - Incluir carne de peixe na sua dieta alimentar é: & Muito desnecessário - Muito necessário & 4,13 & 0,98 \\
ATT4 - Incluir carne de peixe na sua dieta alimentar é: & Pouco importante - Muito importante & & \\
& & 4,25 & 0,90 \\
\hline $\boldsymbol{\alpha}$ de Cronbach (ATT) = 0,90 & & \\
\hline Média da Atitude (ATT) = 4,23
\end{tabular}

Tabela 5: Escala, média e $\alpha$ de Cronbach para as duas declarações usadas para medir a norma subjetiva dos potenciais consumidores da proteína de peixe na dieta alimentar.

\begin{tabular}{|c|c|c|c|}
\hline Norma Subjetiva (NS) & Escala (1-5) & Média & $\begin{array}{l}\text { Desvio } \\
\text { Padrão }\end{array}$ \\
\hline $\begin{array}{l}\text { NS1 - A maioria das pessoas que são importantes para você, acham que } \\
\text { você deveria incluir a carne de peixe em sua dieta alimentar? }\end{array}$ & $\begin{array}{l}\text { Discordo plenamente - } \\
\text { Concordo plenamente }\end{array}$ & 3,92 & 1,09 \\
\hline $\begin{array}{l}\text { NS2 - A maioria das pessoas das qual você escuta opiniões, aprovariam } \\
\text { que você inclua a carne de peixe em sua dieta alimentar? }\end{array}$ & $\begin{array}{l}\text { Muito improvável - Muito } \\
\text { provável }\end{array}$ & 4,2 & 0,90 \\
\hline \multicolumn{4}{|l|}{$\alpha$ de Cronbach (NS) $=0,76$} \\
\hline Média da Norma Subjetiva (NS) $=4,06$ & & & \\
\hline
\end{tabular}

Para as três declarações utilizadas para medir o controle comportamental percebido, as médias das declarações apresentaram valores altos (Tabela 6). Por outro lado, a declaração CCP3 apresentou a maior média no que tange controle. Assim, os respondentes da amostra percebem que possuem certa capacidade de inserção da proteína de peixe em sua dieta alimentar. O coeficiente $\alpha$ de Cronbach para o constructo controle comportamental percebido foi superior a 0,6 (Tabela 6). Portanto, os resultados para as três declarações utilizadas podem ser somados e a média utilizada para representar esse constructo.

Tabela 6: Escala, média e $\alpha$ de Cronbach para as quatro declarações usadas para medir o controle comportamental percebido dos potenciais consumidores da proteína de peixe na dieta alimentar.

\begin{tabular}{|l|l|l|l|}
\hline Controle Comportamental Percebido (CCP) & Escala (1-5) & Média & $\begin{array}{l}\text { Desvio } \\
\text { Padrão }\end{array}$ \\
\hline $\begin{array}{l}\text { CCP1 - Quanto confiante você se sente para superar obstáculos que } \\
\text { dificultariam para você inserir a carne de peixe em sua dieta alimentar? }\end{array}$ & $\begin{array}{l}\text { Pouco confiante - Muito } \\
\text { confiante }\end{array}$ & 3,85 & 1,15 \\
\hline $\begin{array}{l}\text { CCP2 - Consumir carne de peixe em sua dieta alimentar depende somente } \\
\text { de você? }\end{array}$ & $\begin{array}{l}\text { Discordo plenamente - } \\
\text { Concordo plenamente }\end{array}$ & 3,75 & 1,29 \\
\hline $\begin{array}{l}\text { CCP3 - Para você, inserir carne de peixe em sua dieta alimentar está sob } \\
\text { seu controle? }\end{array}$ & $\begin{array}{l}\text { De maneira nenhuma - } \\
\text { Completamente }\end{array}$ & 3,94 & 1,11 \\
\hline $\boldsymbol{\alpha}$ de Cronbach (CCP) $=\mathbf{0 , 8 4}$ & \multicolumn{2}{|l|}{} \\
\hline Média do Controle Comportamental Percebido (CCP) = 3,84
\end{tabular}

As quatro declarações utilizadas para medir valores saudáveis apresentaram médias altas, sendo a VS1 com o valor mais alto e a VS2 com o valor mais baixo (Tabela 7). Com isso, os potenciais consumidores da proteína de peixe na amostra apresentaram um sentimento positivo em entender a necessidade ou, muitas vezes, a obrigação moral do consumo da proteína de peixe e seus benefícios para a saúde. 0 coeficiente $\alpha$ de Cronbach para o constructo foi superior a 0,6 (Tabela 7). Portanto, os resultados para as três declarações utilizadas podem ser somados e a média utilizada para representá-lo. 
Tabela 7: Escala, média e $\alpha$ de Cronbach para as três declarações usadas para medir valores saudáveis dos potenciais consumidores da proteína de peixe na dieta alimentar.

\begin{tabular}{|c|c|c|c|}
\hline Valores Saudáveis (VS) & Escala (1-5) & Média & $\begin{array}{l}\text { Desvio } \\
\text { Padrão }\end{array}$ \\
\hline $\begin{array}{l}\text { VS1 - Você sente que deve inserir carne de peixe em sua dieta } \\
\text { alimentar? }\end{array}$ & $\begin{array}{ll}\text { Definitivamente não } & - \\
\text { Definitivamente sim } & \end{array}$ & 4,3 & 1,02 \\
\hline $\begin{array}{l}\text { VS2 - Você sente a obrigação de inserir carne de peixe em sua dieta } \\
\text { alimentar? } \\
\text { VS3 - Se você consumir carne de peixe em sua dieta alimentar, irá se } \\
\text { sentir uma pessoa melhor? } \\
\text { VS4 - Se você consumir carne de peixe em sua dieta alimentar, irá } \\
\text { ser uma pessoa mais saudável? }\end{array}$ & $\begin{array}{l}\text { De maneira nenhuma - } \\
\text { Completamente } \\
\text { Pouco provável - Muito provável } \\
\text { Pouco provável - Muito provável }\end{array}$ & $\begin{array}{l}3,45 \\
3,97 \\
4,25\end{array}$ & $\begin{array}{l}1,14 \\
0,97\end{array}$ \\
\hline
\end{tabular}

Os resultados para os coeficientes de Spearman (rs) dos constructos e a correlação com intenção apresentados abaixo na Tabela 8, mostraram que as medidas da ATT, NS, CCP, VS foram positivamente e significativamente correlacionadas com a intenção.

Tabela 8: Médias e coeficiente de Spearman (rs) para a correlação entre atitude, norma subjetiva, controle comportamental percebido, valores saudáveis versus intenção.

\begin{tabular}{|l|l|l|}
\hline Construto & Média & Correlação com Intenção (rs) \\
\hline Atitude (ATT) & 4,23 & $0,76^{*}$ \\
\hline Norma Subjetiva (NS) & 4,06 & $0,53^{*}$ \\
\hline Controle Comportamental Percebido (CCP) & 3,84 & $0,53^{*}$ \\
\hline Valores Saudáveis (VS) & 3,99 & $0,59^{*}$ \\
\hline
\end{tabular}

* Variáveis com $\mathrm{P}<0,05$

\section{Crenças Comportamentais, Crenças Normativas, Crenças de Controle e suas Correlações com os respectivos Construtos da TCP}

As correlações dos construtos atitude, norma subjetiva e controle comportamental percebido com suas respectivas crenças são apresentadas nas tabelas seguintes. Os resultados para os coeficientes de Spearman (rs) apresentados na Tabela 9, mostram que das seis crenças comportamentais (bi $x$ ei) identificadas, três estão positivamente e significativamente correlacionadas com a atitude. Os fatores: Custo elevado na alimentação; Reações adversas (azia etc.) e; Dificuldades de preparo, apresentaram correlação não significativa com a atitude. Portanto, a atitude está correlacionada positivamente com as crenças comportamentais, visto que a atitude não foi rejeitada por apenas três das seis crenças comportamentais.

Tabela 9: Coeficiente de Spearman ( $r s)$ para a correlação entre as crenças comportamentais e atitude.

\begin{tabular}{|l|l|}
\hline Crenças Comportamentais (bi $\boldsymbol{x}$ ei) & Correlação com Atitude (rs) \\
\hline Alimentação mais saudável & $0,74^{*}$ \\
\hline Diversificação de cardápio & $0,67^{*}$ \\
\hline Sensação de saciedade & $0,53^{*}$ \\
\hline
\end{tabular}

* Variáveis com $\mathrm{P}<0,05$

Os resultados para os coeficientes de Spearman (rs) apresentados na Tabela 10, mostram que das três crenças normativas ( $\mathrm{nj} x \mathrm{mj}$ ) identificadas, todas estão positivamente e significativamente correlacionadas com a norma subjetiva. Os resultados para os coeficientes de Spearman (rs) apresentados na Tabela 11, mostram que das quatro crenças de controle (ck $x$ pk) identificadas, todas estão positivamente e significativamente correlacionadas com o controle comportamental percebido. 
Tabela 10: Coeficiente de Spearman (rs) para a correlação entre as crenças normativas e norma subjetiva.

\begin{tabular}{|l|l|}
\hline Crenças Normativas (nj $\boldsymbol{x}$ $\mathbf{m}$ ) & Correlação com Norma Subjetiva (rs) \\
\hline Profissionais da saúde & $0,66^{*}$ \\
\hline Família & $0,39^{*}$ \\
\hline Amigos & $0,51^{*}$ \\
\hline
\end{tabular}

* Variáveis com $\mathrm{P}<0,05$

Tabela 11 Coeficiente de Spearman (rs) para a correlação entre as crenças de controle e o controle comportamental percebido.

\begin{tabular}{|l|l|}
\hline Crenças de Controle (ck $\boldsymbol{x}$ pk) & Correlação com Controle Comportamental Percebido (rs) \\
\hline Qualidade na alimentação & $0,62^{*}$ \\
\hline Bom sabor da carne & $0,50^{*}$ \\
\hline Disponibilidade da carne & $0,66^{*}$ \\
Procedência da carne & $0,67^{*}$ \\
\hline
\end{tabular}

* Variáveis com $\mathrm{P}<0,05$

\section{DISCUSSÃO}

Em paralelo ao baixo consumo per capita da proteína de peixe na dieta dos indivíduos do estado de Mato Grosso do Sul (MS), este estudo buscou evidenciar através dos constructos da Teoria do Comportamento Planejado (TCP) a intenção para o consumo de peixe, com vistas a levantar os motivos e principais barreiras para o consumo da carne no estado. O objetivo deste estudo foi investigar se a TCP poderia prever a intenção para o consumo de peixe em uma amostra de consumidores sul-mato-grossenses.

Os resultados forneceram uma compreensão mais clara das intenções/comportamento. Como previsto, todos os constructos da TCP original (atitudes, norma subjetiva e controle comportamental percebido) foram preditores significativos da intenção de consumir a proteína de peixe. Nesta pesquisa, adicionou-se ao modelo original o constructo valores saudáveis que foi importante preditor das intenções de consumo. Como esperado, o mais forte preditor de intenção do consumo da carne de peixe foi a Atitude (ATT). Os consumidores que percebem o consumo da proteína de peixe como saudável apresentaram uma intenção mais forte para consumi-la. Isto confirma descobertas anteriores de Verbeke et al. (2005) sobre a correlação entre atitudes e intenção.

Alimentação mais saudável, diversificação de cardápio e sensação de saciedade são três crenças bem apreciadas pela atitude no consumo da proteína de peixe. As crenças: custo elevado na alimentação; reações adversas (azia etc.) e dificuldades no preparo, não apresentaram correlação significativa em relação a atitude. Logo, para as crenças não significativas os indivíduos não as esperam para tomar a atitude em relação a intenção. Por outro lado, apesar de atitudes em relação a carne de peixe serem relativamente positivas, novas informações sobre a importância do consumo de peixe podem ainda contribuir para atitudes mais positivas.

A Norma Subjetiva (NS) teve correlação positiva sobre a intenção. Assim sendo, enfatizando aos consumidores a importância da proteína de peixe na mesa da família através de especialistas alimentares (e, consequentemente, pela família e amigos) pode ser benéfico para aumentar a norma subjetiva. Estudos anteriores confirmaram a importância da norma subjetiva. De acordo com Thong et al. (2008), a intenção em consumir a carne de peixe é impulsionada de forma significativa pela pressão social, tais como a expectativa da família e 'outros indivíduos importantes' para as pessoas como, por exemplo, amigos. 
Com relação ao Controle Comportamental Percebido (CCP), houve correlação positiva sobre a intenção. Os consumidores que acharam difícil julgar a qualidade na alimentação com a proteína de peixe apresentaram uma intenção menor para o consumo da carne. Devido a este resultado, aumentar o nível de conhecimento sobre a compra e preparo do peixe seria uma alternativa recomendada. Ainda, o bom sabor da carne, a disponibilidade e procedência dela, foram crenças com impacto sobre a intenção, onde os indivíduos veem como limitantes a falta delas para a intenção de consumo. Conforme estudos de Scholderer et al. (2001), eles observaram um impacto significativo da disponibilidade da carne de peixe para a frequência de consumo.

Conforme o constructo adicionado ao modelo original, Valores Saudáveis (VS) foi um importante preditor, estando correlacionado positivamente com a intenção. O sentimento pessoal de responsabilidade e a questão de alimento saudável para a dieta pessoal ou para oferecer à família foi confirmada neste estudo. Baseado em um estudo na Noruega et al. (2001) mostrou que a norma moral, composta neste constructo, foi o segundo mais importante preditor de motivação para o consumo de peixes, sendo, ainda, mais importante do que a atitude. Em relação a saúde, Roininen et al. (1999), indicou que indivíduos mais jovens são pouco influenciados pelos atributos relacionados com a saúde de alimentos ou por mudanças ambientais que poderiam aumentar a conveniência e acesso a escolhas mais saudáveis (WIEGERSMA et al., (2000).

Enquanto muitos estudos buscam determinar a intenção de se realizar um comportamento específico, é de entendimento que a intenção de se realizar determinado comportamento nem sempre se concretiza. Demonstrou-se no presente estudo, correlação positiva entre a intenção e consumo da proteína de peixe. Por fim, a intenção dos indivíduos para o consumo da carne de peixe na dieta alimentar foi encontrada como um preditor significativo do comportamento, que está de acordo com outros estudos utilizando o modelo da TCP (WONG et al., 2009; KASSEM et al., 2003).

\section{CONCLUSÕES}

O presente estudo mostrou que a TCP se torna um modelo útil para prever a intenção do consumo da proteína de peixe na dieta alimentar de uma amostra de consumidores. A relevância desta pesquisa foi o ensaio de um modelo estendido da TCP, no Mato Grosso do Sul, sendo um estado brasileiro onde o consumo da carne é apoiado, porém ele não atinge os níveis recomendados pela OMS.

Com os resultados, verificou-se que todos os constructos foram correlacionados significativamente com a intenção. Dentro do modelo teórico, levando-se em consideração, para cada constructo (crenças comportamentais, normativas e de controle), as maiores correlações, percebe-se que os fatores que influenciam o consumo de peixe na dieta alimentar da amostra sul-mato-grossense são respectivamente, o fato da alimentação mais saudável, a influência dos profissionais da saúde e a necessidade de procedência da carne.

Além disso, os resultados deste estudo oferecem uma variedade de informações úteis para a criação de campanhas públicas destinadas a aumentar o consumo de peixe. As informações obtidas podem ser aplicadas pelos produtores e vendedores de peixe, especialmente no que tange a criação de estratégias de 
marketing. Por outro lado, existem algumas limitações do estudo atual. Primeiramente, apesar da pesquisa ter sido coletada via empresa especializada, foi baseada em uma técnica de contato on-line, sendo que certas populações são menos propensas a ter acesso à Internet para responder questionários online. Além disso, a utilização de uma amostra não probabilística neste estudo não permite a extrapolação dos resultados para a população em geral.

Estudos futuros devem investigar se existem diferenças na TCP entre os entrevistados com renda variável, local de residência e de gênero, e uma comparação deve ser feita dos entrevistados das regiões centrais e ribeirinhas do Mato Grosso do Sul. Ainda, deve-se buscar novos constructos para o modelo, de forma que representem e sejam de impacto significativo para avaliar as intenções de consumo.

\section{REFERÊNCIAS}

AJZEN, I.. The theory of planned behaviour. Organizational Behaviour and Human Decision Processes, v.50, n.2, p.179211, 1991. DOI: http://doi.org/10.10116/07495978(91)90020-T

AJZEN, I.. Attitudes, personality, and behavior. Londres: McGraw-Hill Education, 2005.

AJZEN, I.. The theory of planned behaviour. In: LANGE, P. A. M.; KRUGLANSKI, A. W.; HIGGINS, A. W. K.; HIGGINS, E. T.. Handbook of theories of social psychology. London, 2012. DOI: http://doi.org/10.4135/9781446249215.n22

AL-LOZI, E.; PAPAZAFEIROPOULOU, A.. Intention-based models: the theory of planned behaviour within the context of IS. Integrated Series in Information Systems, v.2, p.219239, 2012. DOI: http://doi.org/10.1007/978-1-4419-9707$\underline{412}$

BORGES, J. A. R.; LANSINK, A. G. O.; RIBEIRO, C. M.; LUTKE, V.. Understanding farmers' intention to adopt improved natural grassland using the theory of planned behavior. Livestock Science, v.169, p.136-174, 2014. DOI: http://doi.org/10.1016/j.livsci.2014.09.014

BRANDÃO, P. A. O.. Análise do consumo de carne de peixe na cidade de Barra do Garças - MT. Revista Eletrônica Interdisciplinar, v.2, n.14, 2015.

BRASIL. Ministério da Pesca e Aquicultura. Decreto $\mathbf{n}$. 30.691, de 29 de março de 1952 . Aprova o novo Regulamento da Inspeção Industrial e Sanitária de Produtos de Origem Animal. Brasília: DOU, 1952.

BRUIJNIS, M.; HOGEVEEN, H.; GARFORTH, C.; STASSEN, E.. Dairy farmers' attitudes and intentions towards improving dairy cow foot health. Livestock Science, v.155, n.1, 2013. DOI: http://doi.org/10.1016/j.livsci.2013.04.005

BURGER, J.; GOCHFELD, M.. Perceptions of the risks and benefits of fish consumption. Individual choices to reduce risk and increase health benefits. Environmental Research, v.109, n.3, p.343-349, 2009. DOI:

http://doi.org/10.1016/j.envres.2008.12.002

CARVALHO, R.; LEMOS, D.. Aquicultura e consumo de carnes no Brasil e no Mundo. Revista Panorama da Aquicultura, Rio de Janeiro, v.19, n.112, 2009.

COSTA, T. V.; SILVA, R. R. S.; SOUZA, J. L.; BATALHA, O. S.; HOSHIBA, M. A.. Aspectos do consumo e comércio de pescado em Parintins. Boletim do Instituto de Pesca, v.39, n.1, 2013.
CARRIJO-MAUAD, J. R.; DUTRA, F. M.; BINOTTO, E.. Análise comportamental do consumidor de peixe em Dourados/MS. In: CONBRAVET, 40. Anais. Salvador, 2013.

DYERBERG, J.; BANG, H. O.. Haemostatic function and platelet polyunsaturated fatty acids in Eskimos. Lancet, v.314, n.8140, p.433-435, 1979. DOI:

http://doi.org/10.1016/S0140-6736(79)91490-9

ESTIMA, C. C. P.; PHILIPPI, S. T.; ALVARENGA, M. S.. Fatores determinantes do consumo alimentar: por que os indivíduos comem o que comem?. Revista Brasileira Nutrição Clin., v.4, n.24, 2009.

FURST, T.; CONNORS, M.; BISSOGNI, C. A.; SOBAL, J.; FALK, L. W.. Food choice: a conceptual model of the process. Appetite, v.26, n.3, p.247-266, 1996. DOI: http://doi.org/10.1006/appe.1996.0019

FALK, L. W.; SOBAL, J.; BISSOGNI, C. A.; CONNORS, M.; DEVINE, C. M.. Managing health eating: definitions, classifications and strategies. Health Educ Behav, v.28, n.4, 2001. DOI: http://doi.org/10.1177/109019810102800405

FISHBEIN, M.; AJZEN, I.. Predicting and changing behavior: The reasoned action approach. New York: Taylor \& Francis Group, 2010. DOI: http://doi.org/10.4324/9780203838020

FAO. Food and Agriculture Organization. State of world fisheries and aquaculture, opportunities and challenges. Rome: FAO, 2014.

FAO. Food and Agriculture Organization. State of world fisheries and aquaculture. Rome: FAO, 2018.

GRACIA, F.. A indústria de frutos do mar. In: REUNIÃO INTERAMERICANA A NÍVEL MINISTERIAL SOBRE SAÚDE E AGRICULTURA, 13. Anais. Washington, 2003.

GONÇALVES, A. A.; PASSOS, M. G.; BIEDRZYCKI, A.. Tendência do consumo de pescado na cidade de Porto Alegre: um estudo através de análise de correspondência. Estudos Tecnológicos, v.4, p.21-36, 2008.

GAVIGLIO, A.; DEMARTINI, E.; MAURACHER, C.; PIRANI, A.. Consumer perception of diferent species and presentation forms of fish: An empirical analysis in Italy. Food Quality and Preference, v.36, p.33-49, 2014. DOI: http://doi.org/10.1016/i.foodqual.2014.03.002

IBGE. Instituto Brasileiro de Geografia e Estatística. Pesquisa de Orçamentos Familiares 2008-2009: Despesas, 
Rendimentos e Condições de Vida. Rio de Janeiro: IBGE, 2010.

IBGE. Instituto Brasileiro de Geografia e Estatística. Pesquisa da Produção da Pecuária Municipal. Rio de Janeiro: IBGE, 2013.

KRIS-ETHERTON, P. M.; HARRIS, W. S.; APPEL, L. J.. American Heart Association. Fish consumption, fish oil, omega-3 fatty acids, and cardiovascular disease. Circulation, 2002. DOI: http://doi.org/10.1161/01.ATV.0000038493.65177.94

KASSEM, N. O.; LEE, J. W.; MODESTE, N. N.; JOHNSTON, P. K.. Refrigerante, compreensão do consumo entre adolescentes do sexo feminino usando a Teoria do Comportamento Planejado. Pesquisa de Educação em Saúde, 2003.

LOPES, I. G.; OLIVEIRA, R. G.; RAMOS, F. B.. Perfil do consumo de peixes pela população brasileira. Biota Amazônia, v.6, n.2, 2016.

MCEACHAN, R. R. C.; CONNER, M.; TAYLOR, N. J.; LAWTON, R. J.. Prospective prediction of health-related behaviours with the Theory of Planned Behaviour: a metaanalysis. Health Psychology Review, 2011. DOI: http://doi.org/10.1080/17437199.2010.521684

MPA. Ministério da Pesca e Aquicultura. Plano de Desenvolvimento da Aquicultura Brasileira 2015/2020. Brasil: Governo Federal, 2015.

NOVAES, A. L.. Comportamento do consumo de carne bovina e hortaliças no Brasil: perfil dos consumidores. Campo Grande: Universidade Federal de Mato Grosso do Sul, 2006.

OLSEN, S. O.. Consumer involvement in seafood as family meals in Norway: an application of the expectancy-value approach. Appetite, v.36, n.2, p.173-186, 2001. DOI: http://doi.org//10.1006/appe.2001.0393

OLSEN, S. O.. Antecedents of seafood consumption behaviour: An overview. Journal of Aquatic Food Product Technology, v.12, n.3, 2004. DOI: http://doi.org//10.1300/J030v13n03 08

OETTERER, M.. Industrialização do pescado cultivado. Guaíba: Editora Agropecuária, 2002.

PHILIPPI, S. T.. Pirâmide dos alimentos: fundamentos básicos da nutrição. São Paulo: Manole, 2008.

PERUGINI, M.; BAGOZZI, R. P.. The role of desires and anticipated emotions in goal-directed behaviours: broadening and deepening the theory of planned behaviour. British Journal of Social Psychology, v.40, n.1, p.79-98, 2001. DOI: http://doi.org/10.1348/014466601164704

REYNOLDS, P. D.. A primer in theory construction. Indianapolis: Bobs Merrill Company, 1971.

ROININEN, K.; LAHTEENMAKI, L.; TUORILA, H.. Quantification of Consumer Attitudes to Health and Hedonic Characteristics of Foods. Appetite, v.33, n.1, p.71-88, 1999. DOI: http://doi.org/10.1006/appe.1999.0232

STANSBY, M. E.. Polyunsaturates and fat in fish flesh. J Am Diet Assoc., v.63, n.6, p.625-630, 1973.

SCHOLDERER, J.; GRUNERT, K. G.. Does generic advertising work? A systematic evaluation of the Danish campaign for fresh fish. Aquaculture Economics \& Management, 2001. DOI: $10.1080 / 13657300109380293$

SOCCOL, M. C. H.; OETTERER, M. Seafood as functional food. Brazilian Archives of Biology and Technology, v.46, n.3, 2003. DOI: http://doi.org/10.1590/s1516$\underline{89132003000300016}$

SANTOS, C. A. M. L.. A qualidade do pescado e a segurança dos alimentos. In: SIMPÓSIO DE CONTROLE DO PESCADO. Anais. São Paulo: Instituto da Pesca, 2006.

SARTORI, A. G. O.; AMÂNCIO, R. D.. Pescado: importância nutricional e consumo no Brasil. Segurança Alimentar e Nutricional, v.19, n.2, 2012

TRONDSEN, T.; BRAATEN, T.; LUND, E.; EGGEN, A. E.. Consumption of seafood the influence of overweight and health beliefs. Food Quality and Preference, v.15, n.4, p.361-374, 2004b. DOI: http://doi.org/10.1016/S09503293(03)00083-1

THONG, N. T.; OLSEN, S. O.. Motivation to consume fish (seafood) in Vietnam. International Institute of Fisheries Economics \& Trade. In: CONF IIFET,14. Anais. 2008.

TOMIC, M.; MATULIC, D.; JELIC, M.. What determines fresh fish consumption in Croatia?. Appetite, 2016. DOI: http://doi.org/10.1016/i.appet.2015.12.019

VERBEKE, W.; \& VACKIER, I. Individual determinants of fish consumption: application of the theory of planned behaviour. Appetite, v.106, p.13-22, 2005. DOI: http://doi.org/10.1016/j.appet.2004.08.006

WAUTERS, E.; BIELDERS, C.; POESEN, J.; GOVERS, G.; MATHIJS, E. Adoption of soil conservation practices in Belgium: an examination of the theory of planned behaviour in the agri-environmental domain. Land use policy, v.27, n.1, 2010. DOI: http://doi.org/10.1016/i.landusepol.2009.02.009

WIEGERSMA, P. A.; HOFMAN, A.; ZIEALHUIS, G. A. Prevention of unhealthy behaviour by youth health care in The Netherlands. Journal of Medicine, v.22, n.3, p.386-392, 2000. DOI: http://doi.org/10.1093/pubmed/22.3.386

WONG, C. L.; MULLAN, B. A.. Predicting breakfast consumption: An application of the theory of planned behaviour and the investigation of past behaviour and executive function. British Journal of Health Psychology, v.14, n.3, p.489-504, 2009. DOI: http://doi.org/10.1348/135910708X360719

A CBPC - Companhia Brasileira de Produção Científica (CNPJ: 11.221.422/0001-03) detém os direitos materiais desta publicação. Os direitos referem-se à publicação do trabalho em qualquer parte do mundo, incluindo os direitos às renovações, expansões e disseminações da contribuição, bem como outros direitos subsidiários. Todos os trabalhos publicados eletronicamente poderão posteriormente ser publicados em coletâneas impressas sob coordenação da Sustenere Publishing, da Companhia Brasileira de Produção Científica e seus parceiros autorizados. Os (as) autores (as) preservam os direitos autorais, mas não têm permissão para a publicação da contribuição em outro meio, impresso ou digital, em português ou em tradução. 